\title{
Diffuse large B-cell lymphoma with both CD5 and cyclin D1 expression-a case report and review of the literature
}

\author{
Ashley Schneider • Paul Meyer • Dominick DiMaio • \\ Kai Fu
}

Received: 7 July 2010 / Accepted: 5 October 2010 /Published online: 5 November 2010

(C) Springer-Verlag 2010

\begin{abstract}
Diffuse large B-cell lymphoma (DLBCL) is the most common type of non-Hodgkin's lymphoma (NHL), representing approximately $25-30 \%$ of newly diagnosed adult NHL in Western countries. CD5-positive DLBCL has been reported in $10 \%$ of cases in some series. DLBCL with cyclin D1 expression has also been reported in the literature. These cases may sometimes be confused with mantle cell lymphoma (MCL), especially blastoid variant MCL, morphologically and immunophenotypically. Herein, we present an unusual case of a 41-year-old female without significant medical history who presented with a right facial/parotid mass. Morphologically, the tumor showed a diffuse growth pattern of large lymphoid cells with vesicular nuclei, consistent with a DLBCL. Immunostains, however, showed that the tumor cells were positive for both CD5 and cyclin D1. Fluorescence in situ hybridization studies showed a rearrangement of the Bcl-6 gene (3q27) in $29.5 \%$ of cells but no evidence of $\mathrm{IgH} / \mathrm{Bcl}-1$ [t(11;14)] or $\mathrm{IgH} / \mathrm{Bcl}-2$ [t(14;18)] rearrangement. Immunostain for SOX11 was also performed and is negative. The clinicopathologic features of this CD5- and cyclin D1-positive DLBCL are described, and the differential diagnosis between DLBCL and MCL is discussed.
\end{abstract}

Keywords Diffuse large B-cell lymphoma - Cyclin D1 . CD5 - Mantle cell lymphoma

A. Schneider $\cdot$ P. Meyer $\cdot$ D. DiMaio $\cdot$ K. Fu $(\triangle)$

Department of Pathology and Microbiology,

University of Nebraska Medical Center,

983135 Nebraska Medical Center,

Omaha, NE 68198-3135, USA

e-mail: kfu@unmc.edu

\section{Introduction}

Diffuse large B-cell lymphoma (DLBCL) is the most common type of non-Hodgkin lymphoma (NHL) and accounts for approximately $25-30 \%$ of new diagnoses of adult NHL in Western countries [1]. Morphologically, the tumors typically demonstrate a diffuse proliferation pattern and consist of large cells with vesicular nuclei, prominent nucleoli, and abundant cytoplasm. Immunophenotypically, the tumor cells are positive for CD20 but negative for CD3. Bcl-6 is estimated to be positive in $60-90 \%$ of cases and MUM1 in $35-65 \%$ of cases. The reported frequency of CD10 varies from $30-60 \%$ and is associated with the germinal center subtype (GCB-DLBCL). Aberrant CD5 expression has been reported in up to $10 \%$ of cases $[1,2]$. Cyclin D1 expression has been associated with only 12 reported cases of DLBCL in the literature [3-5]. Cytogenetically, the Bcl-6 gene (3q27) rearrangement is the most common abnormality in DLBCL [1].

Mantle cell lymphoma (MCL) comprises $3-10 \%$ of NHL and is typically composed of monomorphic small to medium-sized lymphoid cells with irregular nuclear contours and inconspicuous nucleoli [6]. The tumor cells in almost all MCL cases are positive for cyclin D1, and many are positive for CD5. SOX11 is a new biomarker that has been shown to be highly specific for MCL, as it is detected in $93 \%$ of cyclin D1-positive cases [7, 8]. Lambda light chain restriction is more frequently seen in MCL, and MCL cells typically show moderate to strong intensity of surface immunoglobulin [6,9]. MCL typically demonstrates a $\mathrm{t}(11 ; 14)$ translocation, and rearrangements of the BCL-6 gene only rarely occur in MCL [10]. The rare cases of MCL that are negative for cyclin D1 and lack the $t(11 ; 14)$ have an expression profile that is otherwise indistinguishable from 
conventional MCL and express SOX11 [9]. Blastoid MCL is characterized by increased nuclear size, pleomorphism, and increased mitotic activity and is typically cyclin D1 and CD5 positive, but aberrant expression of CD10 and loss of CD5 have also been described [6].
Herein, we present an unusual case of DLBCL that is positive for both CD5 and cyclin D1. The diagnosis of DLBCL is supported by large centroblastic morphology, immunoreactivity of Bcl-6 and MUM1, negativity for SOX11, and lack of the $\mathrm{t}(11 ; 14)$ translocation.
Fig. 1 H \& E sections (a, 200× magnification; b, $400 \times$ ) show a diffuse infiltrate of large pleomorphic lymphoid cells with admixed "pink" histiocytes. The tumor cells are positive for CD20 (c, 200×) but negative for CD3 (d, 400×). The majority of the cells show CD5 positivity (inset in d, 400×) and 30\% of the CD20-positive cells show cyclin D1 expression as seen in a cyclin D1 (nuclear, brown chromogen)/CD20 (cell membrane, red chromogen) dual stain $(\mathbf{e}, 400 \times)$. The tumor cells are negative for SOX11 (f, 400×), but salivary gland ductal structures stain positively. The tumor cells also express BCL6 (g, 200×) and MUM1 (h, 200×)
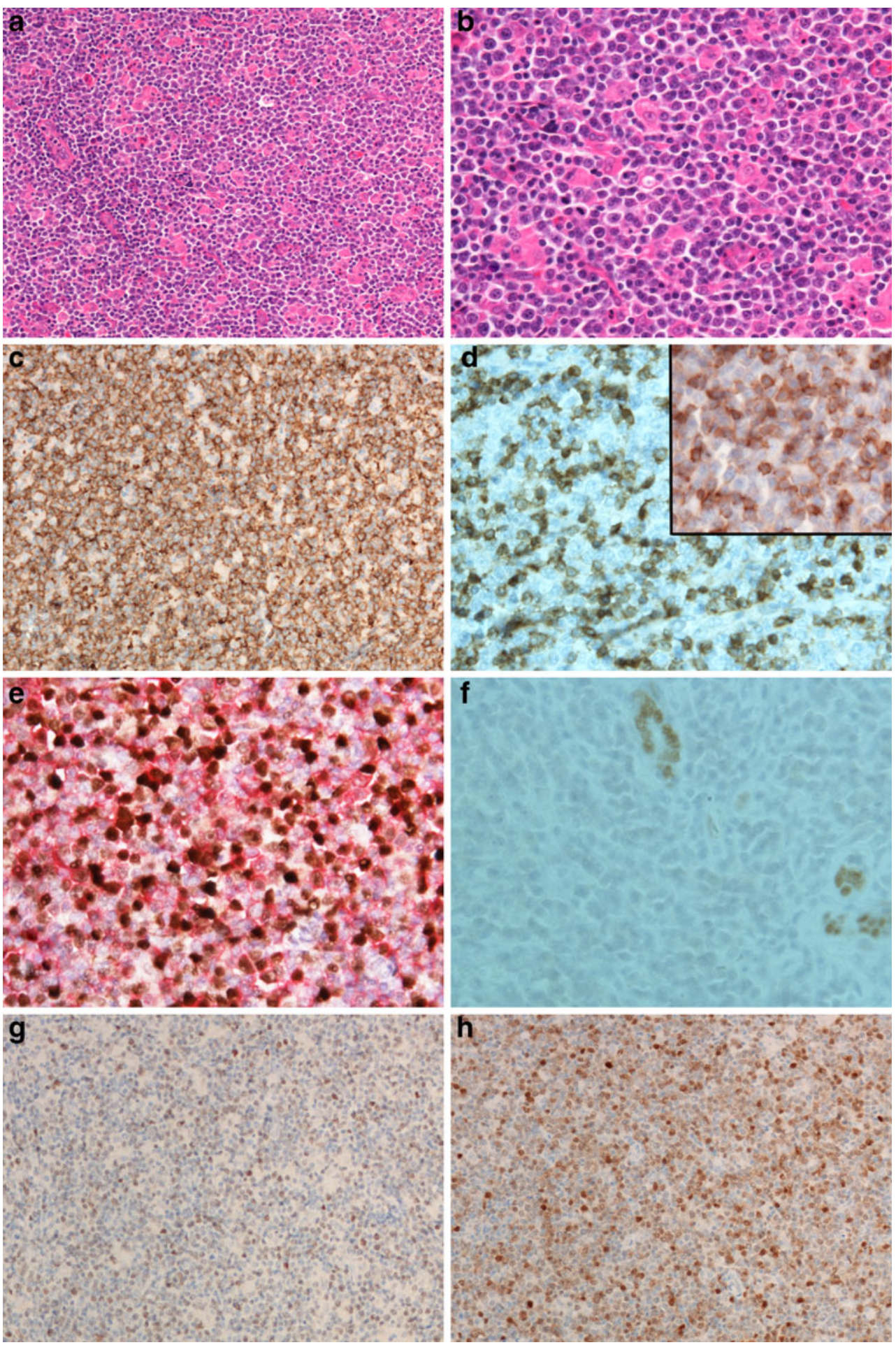


\section{Case report}

The patient is a 41-year-old female without a significant past medical history who initially presented with a right facial mass. The patient attributed this to an upper respiratory illness until several months later when she noticed an increased size of the mass. Upon examination a $3.0 \times 2.0-\mathrm{cm}$ right facial nodule was noted within the parotid tail. The lesion was firm and tender to palpation. Right cervical lymphadenopathy was also present. The right parotid tail and right jugular lymph nodes were excised, and sections demonstrated atypical medium- to large-sized lymphoid cells with moderate amount of cytoplasm, vesicular chromatin, and variably prominent nucleoli. The tumor cells proliferated in a diffuse pattern that obliterated normal nodal architecture. Numerous epithelioid histiocytes were also present (Fig. 1a, b). Flow cytometry of the parotid mass showed a CD5-positive mature B-cell population expressing CD19, CD20, CD22, CD38, and FMC7, with low-density surface kappa light chain expression. Immunohistochemical stains show that the tumor cells were positive for CD20 (Fig. 1c), but negative for CD3 (Fig. 1d). The cells were also weakly positive for CD5 (Fig. 1d inset). Cyclin D1 positivity was seen in approximately $30 \%$ of neoplastic cells with heterogeneous reactivity. A cyclin D1/ CD20 dual stain specifically demonstrated positivity for cyclin D1 in the neoplastic B cells (Fig. 1e). Additionally, the tumor cells were positive for CD43, Bcl-2, Bcl-6 (Fig. 1g), and MUM1 (Fig. 1h), but negative for CD10 and SOX11 (Fig. 1f). Fluorescence in situ hybridization (FISH) studies showed a rearrangement of the Bcl-6 gene (3q27) in
$29.5 \%$ of cells and a rearrangement of $\operatorname{IgH}(14 \mathrm{q} 32)$ in $21.5 \%$ of cells. There was no evidence of $\mathrm{IgH} / \mathrm{Bcl}-1$ [ $\mathrm{t}$ $(11 ; 14)]$ or $\mathrm{IgH} / \mathrm{Bcl}-2[\mathrm{t}(14 ; 18)]$ rearrangement. A diagnosis of DLBCL was rendered. The patient was staged at Ann Arbor stage IIA clinically. The patient received six cycles of dose-adjusted etoposide, prednisone, vincristine, cyclophosphamide, and doxorubicin with rituximab infusional therapy (EPOCH-R) with complete response. A PET scan performed 6 months later showed no evidence of recurrent lymphoma.

\section{Discussion}

Herein, we report a case of DLBCL with aberrant expression of both CD5 and cyclin D1. The diagnosis of DLBCL was supported by combined clinical, morphological, immunophenotypic, and molecular cytogenetics findings. It is important to recognize that this case could be easily confused with a blastoid MCL due to aberrant expression of cyclin D1 and CD5. The relatively young age, female gender, and localized disease favor a diagnosis of DLBCL over MCL clinically. Centroblastic morphology, strong expression of BCL-6 and MUM1, and dim kappa expression support the diagnosis of DLBCL. The heterogeneous expression of cyclin D1 also favors a DLBCL. In cyclin D1-positive MCL, the staining pattern is expected to be strong, uniform, and in greater than $90 \%$ of tumor cells. In cyclin D1-negative MCL, the staining pattern is expected to be entirely negative. In our case, approximately $30 \%$ of cells are positive for cyclin D1 and show marked

Table 1 Reported cases of cyclin D1-positive DLBCL

\begin{tabular}{|c|c|c|c|c|c|}
\hline Case & Cyclin D1 percent staining & CD5 & $\mathrm{t}(11 ; 14)$ & Bcl-6 IHC & MUM1 IHC \\
\hline Ehinger 1 & "Weak, diffuse" & Negative & Abnormal cyclinD1 gene & Negative & Positive \\
\hline Ehinger 2 & $<30 \%$ & Negative & Additional cyclinD1 gene & Negative & Positive \\
\hline Ehinger 3 & $<30 \%$ & Negative & Additional cyclinD1 gene & Focal & Focal \\
\hline Ehinger $4^{\mathrm{a}}$ & "Strong, diffuse" & Negative & Present & Negative & Negative \\
\hline Ehinger 5 & $<30 \%$ & Negative & Negative & Focal & Focal \\
\hline Ehinger 6 & $<30 \%$ & Negative & Negative & Focal & Positive \\
\hline Ehinger 7 & $<30 \%$ & Negative & Negative & Positive & Negative \\
\hline Ehinger 8 & $<30 \%$ & Negative & NP & Positive & Negative \\
\hline Ehinger 9 & $<30 \%$ & Negative & NP & Positive & Positive \\
\hline Ehinger 10 & "Weak, diffuse" & Negative & $\mathrm{NP}$ & Positive & $\mathrm{NP}$ \\
\hline Rodriguez-Justo & $60 \%$ & Negative & Negative & Positive & Positive \\
\hline Teruya-Feldstein & $40 \%^{\mathrm{b}}$ & Negative & NP & Positive & Positive \\
\hline
\end{tabular}

$N P$ not performed, $I H C$ immunohistochemistry

${ }^{\text {a }}$ Possibly a blastoid mantle cell lymphoma

${ }^{\mathrm{b}}$ Percentage staining based on published photomicrograph 
heterogeneity. This is not consistent with either expected pattern for MCL. It is also important to note that histiocytes may stain for cyclin D1. As this case is rich in histiocytes, one must identify positivity specifically in neoplastic cells; staining in stromal cells or histiocytes should not be included in the estimated percentage of staining. The cyclin D1/CD20 dual stain demonstrates cyclin D1 expression in the neoplastic B cells. The tumor cells are negative for SOX11, a new and specific marker for MCL diagnosis. Rearrangement of the Bcl-6 gene (3q27) detected by FISH but not a $\mathrm{t}(11 ; 14)$ also supports DLBCL over MCL.

In the literature, there are three reports containing 12 cases of cyclin D1-positive DLBCL (Table 1) [3-5]. FISH studies demonstrated absence of the $\mathrm{t}(11 ; 14)$ translocation in 11 of the 12 cases. The remaining case (case 4) which was positive for the $\mathrm{t}(11 ; 14)$, and showed strong cyclin D1 positivity, may have been a misdiagnosed MCL [11]. In the $\mathrm{t}(11 ; 14)$-negative cases, cyclin D1 expression ranged from $<30 \%$ to $60 \%$ of the tumor cells. All 12 cases were negative for CD5. Ehinger found that $10(4.3 \%)$ of 231 cases of DLBCL cases were positive for cyclin D1 and none were positive for CD5. Rodriguez-Justo and Teruya-Feldstein each presented a case of cyclin D1-positive DLBCL [3, 4]. Comparison of these 12 cases show that, excluding the misdiagnosed MCL, either Bcl-6 or MUM1 was expressed [2]. These cases illustrate how cyclin D1-positive DLBCL may best be differentiated from MCL. Blastoid MCL is most likely to be confused with DLBCL due to large nuclear size and lack of $\mathrm{CD} 5$ expression. As previously discussed, Bcl-6 and MUM1 positivity suggest DLBCL, while the presence of $t(11 ; 14)$ is consistent with MCL [5]. Zhang et al. have also reported five cases of CD5 and cyclin D1 positive DLBCL and concluded that these were transformed from MCL; however, analysis for $t(11 ; 14)$ was not performed [11]. Since our case shows no evidence of the $t(11 ; 14)$, a transformation from MCL is unlikely.

There are multiple reported cases of CD5-positive DLBCL in the literature, and it is actually estimated that $10 \%$ of cases of DLBCL will be positive for CD5 [1,2, 12, 13]. CD5-positive DLBCL are typically distinguished from MCL by morphology and lack of cyclin D1 expression.

In conclusion, CD5-positive and cyclin D1-positive DLBCLs do exist. The patient's age, female gender, morphologic features, variable staining for cyclin D1, positivity for BCL-6 and/or MUM1, negativity for SOX11, and the lack of $t(11 ; 14)$ help to differentiate these cases from a blastoid MCL. The presence of Bcl-6 (3q27) rearrangements would further support a diagnosis of DLBCL instead of blastoid MCL.
Conflict of interest The authors declare that they have no conflict of interest.

\section{References}

1. Stein H, Warnke RA, Chan WC, Jaffe ES, Chan JKC, Gatter KC, Campo E (2008) Diffuse large B-cell lymphoma, not otherwise specified. In: Fred T, Bosman ESJ, Sunil R. Lakhani, Hiroko Ohgaki (eds) WHO classification of tumours of haematopoietic and lymphoid tissues. World Health Organization classification of tumours, 4th edn. International Agency for Research on Cancer, Lyon, pp 233-237

2. Kroft SH, Howard MS, Picker LJ, Ansari MQ, Aquino DB, McKenna RW (2000) De novo CD5+ diffuse large B-cell lymphomas. A heterogeneous group containing an unusual form of splenic lymphoma. Am J Clin Pathol 114(4):523-533

3. Rodriguez-Justo M, Huang Y, Ye H, Liu H, Chuang SS, Munson P, Prada-Puentes C, Kim I, Du MQ, Bacon CM (2008) Cyclin D1positive diffuse large B-cell lymphoma. Histopathology 52(7):900-903

4. Teruya-Feldstein J, Gopalan A, Moskowitz CH (2009) CD5 negative, cyclin D1-positive diffuse large B-cell lymphoma (DLBCL) presenting as ruptured spleen. Appl Immunohistochem Mol Morphol 17(3):255-258

5. Ehinger M, Linderoth J, Christensson B, Sander B, Cavallin-Stahl E (2008) A subset of CD5-diffuse large B-cell lymphomas expresses nuclear cyclin D1 with aberrations at the CCND1 locus. Am J Clin Pathol 129(4):630-638

6. Swerdlow SH, Campo E, Seto M, Muller-Hermelink HK (2008) Mantle cell lymphoma. In: WHO classification of tumours of haematopoietic and lymphoid tissues. World Health Organization classification of tumours, 4th edn. International Agency for Research on Cancer, Lyon, pp 229-232

7. Mozos A, Royo C, Hartmann E, De Jong D, Baro C, Valera A, Fu $\mathrm{K}$, Weisenburger DD, Delabie J, Chuang SS, Jaffe ES, RuizMarcellan C, Dave S, Rimsza L, Braziel R, Gascoyne RD, Sole F, Lopez-Guillermo A, Colomer D, Staudt LM, Rosenwald A, Ott G, Jares P, Campo E (2009) SOX11 expression is highly specific for mantle cell lymphoma and identifies the cyclin D1-negative subtype. Haematologica 94(11):1555-1562

8. Dictor M, Ek S, Sundberg M, Warenholt J, Gyorgy C, Sernbo S, Gustavsson E, Abu-Alsoud W, Wadstrom T, Borrebaeck C (2009) Strong lymphoid nuclear expression of SOX11 transcription factor defines lymphoblastic neoplasms, mantle cell lymphoma and Burkitt's lymphoma. Haematologica 94(11):1563-1568

9. Campo E, Raffeld M, Jaffe ES (1999) Mantle-cell lymphoma. Semin Hematol 36(2):115-127

10. Camacho FI, Garcia JF, Cigudosa JC, Mollejo M, Algara P, RuizBallesteros E, Gonzalvo P, Martin P, Perez-Seoane C, SanchezGarcia J, Piris MA (2004) Aberrant BCL6 protein expression in mantle cell lymphoma. Am J Surg Pathol 28(8):1051-1056

11. Zhang A, Ohshima K, Sato K, Kanda M, Suzumiya J, Shimazaki K, Kawasaki C, Kikuchi M (1999) Prognostic clinicopathologic factors, including immunologic expression in diffuse large B-cell lymphomas. Pathol Int 49(12):1043-1052

12. Matolcsy A, Chadburn A, Knowles DM (1995) De novo CD5positive and Richter's syndrome-associated diffuse large $\mathrm{b}$ cell lymphomas are genotypically distinct. Am J Pathol 147(1):207-216

13. Yamaguchi M, Seto M, Okamoto M, Ichinohasama R, Nakamura N, Yoshino T, Suzumiya J, Murase T, Miura I, Akasaka T, Tamaru J, Suzuki R, Kagami Y, Hirano M, Morishima Y, Ueda R, Shiku H, Nakamura S (2002) De novo CD5+ diffuse large B-cell lymphoma: a clinicopathologic study of 109 patients. Blood 99 (3):815-821 